The nature and physiological importance of the substance are unknown. Its presence in bile and the absence of correlation between the concentration of the substance in plasma and hyperbilirubinaemia probably indicate that other substances-for example, bile acidsmay be interfering with the digoxin assay. Against this assumption, however, is the presence of digoxin like immunoreactive substance in premature infants and patients with renal failure, ${ }^{23}$ conditions in which bile acid concentrations are normal. Endogenous digoxin like immunoreactive substance has been reported in animals, ${ }^{45}$ and it has been suggested that it may have a role in controlling extracellular fluid volume.

Whatever the nature of digoxin like immunoreactive substance, its presence in plasma may pose serious problems in interpreting plasma digoxin concentrations, which are usually maintained within a narrow therapeutic range. Our observations indicate that fluorescence polarisation does not measure digoxin like immunoreactive substance and seems to be the method of choice for digoxin measurements in liver disease.

1 Bellar GA, Smith TW, Abelmann WH, et al. Digitalis intoxication-a prospective clinical study with serum level correlations. N Engl $\mathcal{F}$ Med $1971 ; 284: 989-93$. Graves SW, Brown B, Valdes R. An endogenous digoxin-like substance in patients with renal impairment. Ann Intern Med 1983;99:604-8.

udek MR, Seccombe DW, Whitfield MF, et al. Digoxin-like immunoreactivity in premature and full

4 Gruber KA, Whitaker JM, Buckalew VM. Endogenous digitalis-like substance in the plasma of volume-expanded dogs. Nature 1980;287:743-4.

in the plasma of volume-expanded dogs. Nature 1980;287:743-4. genous digoxin-like factor in hypertensive monkeys. Hypertension 1982;4: 348-54.

(Accepted 21 November 1984)

Department of Pathology, University of Ottawa School of Medicine, and Section of Clinical Biochemistry, Ottawa General Hospital, Ottawa, Canada

AMIN A NANJI, MD, FRCP(C), section head

DONALD C GREENWAY, PHD, biochemist

Correspondence to: Dr Amin A Nanii, Section of Clinical Biochemistry, Ottawa General Hospital, Ottawa K1H 8L6, Canada.

\section{Leishmania braziliensis braziliensis infection of the nipple}

We have not been able to trace a published reference to leishmaniasis of the nipple. We recently saw two cases in the region of Três Braços, Bahia State, Brazil. Leishmania braziliensis braziliensis was isolated from this site in a 37 year old man. A lactating mother also had a nipple granuloma. The same organism was isolated from her 3 month old child, who developed a lesion on the upper lip.

\section{Case histories}

Case 1-A 37 year old man from Coxa da Onça farm, Jiquiriçá, had a large ulcer $(3 \times 7 \mathrm{~cm})$ of seven months' duration over the xiphisternum. Three months later three small granulomas under a centimetre in size appeared on the left forehead. At the same time his right nipple became hard and painful. There was no other history of skin ulceration, and no oronasal lesion was present. The leishmanin skin test reaction was strongly positive at 48 hours $(15 \mathrm{~mm})$. The indirect immunofluorescence antibody test for leishmaniasis using an amastigote antigen of $L$ mexicana amazonensis reached a titre of $1 / 80$. Triturated biopsy material from the breast lesion inoculated into a hamster resulted in the isolation of a parasite characterised as $L$ braziliensis braziliensis by immunofluorescence using specific monoclonal antibody. Treatment with three courses of meglumine antimonate (Glucantime) $28 \mathrm{mg} / \mathrm{kg}$ daily for 10 days resulted in resolution of all lesions except the nipple. Despite a further two courses of the drug this lesion persisted. One year after he was first seen the nipple granuloma was larger and associated with lymphadenopathy. As he refused admission to hospital for more intensive treatment we decided to excise the nipple, although the histological picture was inflammatory granuloma with no evidence of malignancy. Initial biopsy showed some necrosis and poorly organised granuloma in the nipple. The surgical specimen, however, contained mature granuloma rich in Langhans giant cells. There was no sign of healing and the inflammation was widely distributed in the mammary tissue. Pseudoepitheliomatous hyperplasia was present but there was no evidence of malignant change.

Case 2-A 35 year old woman from Serra do Homen farm, Corte da Pedra, consulted us because of a three week history of swelling of the lip of her 3 month old child (figure). Biopsy was not permitted but needling of the upper lip showed amastigotes in the Giemsa stained smear. Five other small granulomas were present on the head (two), trunk (two), and right leg. Biopsy of the leg lesion showed an exudative cellular infiltrate with scanty parasites. The organism recovered by hamster inoculation from this lesion was typed as $L$ braziliensis braziliensis. The leishmanin skin test result was negative but a 1/320 dilution of sera yielded leishmanial fluorescent antibodies. Examination of the mother disclosed multiple lesions. The largest $(3.0 \times 1.5 \mathrm{~cm})$ on the left arm had been present for four months and had closed after application of battery acid, although the border was still active. Biopsy of this border showed a granuloma with foci of necrosis and scanty parasites which were not isolated on hamster inoculation. Two

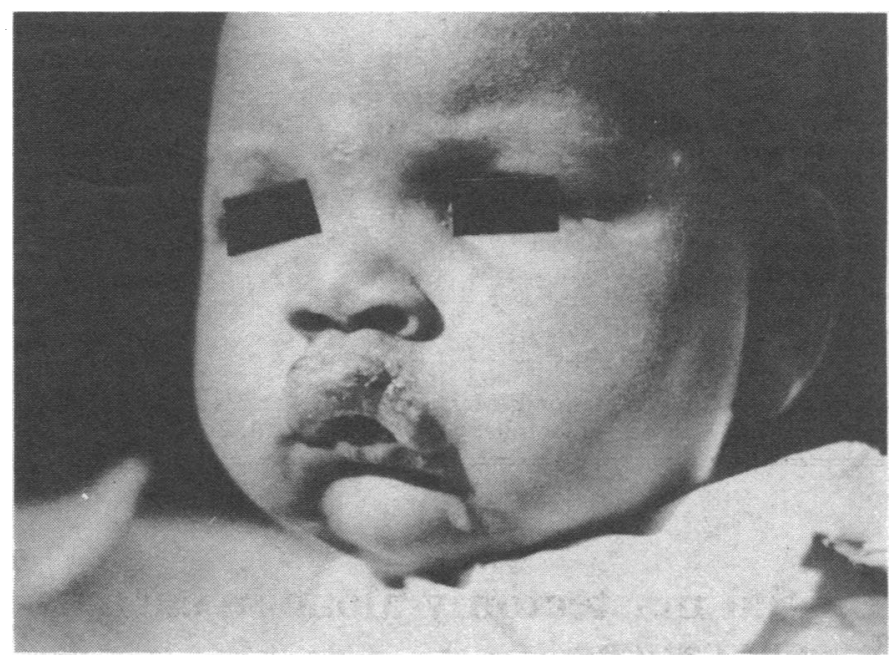

Case 2. Primary lesion of upper lip in 3 month old child from whom $L$ braziliensis braziliensis was recovered. Secondary glabellar lesion evident.

month old lesions were present on the right cheek and right nipple. The nipple was indurated, swollen, and painful. The mother was lactating and no biopsy or needling was permitted. She was expressing the breast. The leishmanin skin test gave a positive reaction but no circulating antibodies could be detected. Mother and child responded well to meglumine antimonate $28 \mathrm{mg} / \mathrm{kg}$ daily for 10 days, repeated on two further occasions. On follow up a year later, however, while the mother remained asymptomatic, the child's lip lesion had returned and was more extensive than before. She was given further treatment.

\section{Comment}

We have isolated $L$ braziliensis braziliensis from $95 \%$ of our patients examined in the area. ${ }^{1}$ The commonest presentation is as a single large ulcer on the lower leg. ${ }^{2}$ One third of patients with skin leishmaniasis, however, have multiple lesions. Of these 59 patients, 38 had a lesion on the leg, 18 on the trunk, 17 on the arm, and 12 on the head. We have recognised nipple leishmaniasis only in the two cases described.

Neither of the two nipple lesions ulcerated and it may be that we have missed other cases for want of specific palpation of this structure. We shall do nipple palpation in all patients with multiple skin lesions due to leishmaniasis in the future. The nipple is usually covered in our patients, and we have never seen a primary lesion. Leishmaniasis of the breast was referred to as a secondary lesion in two patients in a Mexican series, but it was not clear if the nipple was the specific site.

From the course of the disease in our two patients it is clear that the nipple lesion represented a metastasis from the site of primary inoculation. There are reasons why the nipple may be a favourable site for leishmanial growth. The temperature is $1^{\circ} \mathrm{C}$ lower than the body temperature (V A Soares, personal communication), and lower temperatures favour leishmanial growth. ${ }^{3}$ Trauma is another predisposing factor ${ }^{4}$ and must occur in a suckling mother.

Histologically the nipple granuloma in the first patient showed a progression of granuloma formation. Relatively well organised granulomas have been associated in our histological studies with a poor therapeutic response. We really have no idea why the mammary lesion was so refractory to treatment in this patient.

The primary lesion on the upper lip of the suckling child in case 2 suggested an association with the mother's nipple lesion, although 
definite proof was lacking. Transmission to the child may have occurred during suckling. Montenegro showed that leishmaniasis is an inoculable, contagious disease. ${ }^{5} \mathrm{~A}$ case of sexual transmission is documented. A laboratory infection due to contamination with $L$ braziliensis braziliensis has occurred in our own laboratory.

1 Cuba Cuba CA, Marsden PD, Barreto AC, et al. Identification of human stocks of Leishmania sp isolated from patients with mucocutaneous leishmaniasis in

Três Braços, Bahia-Brazil. Trans $R$ Soc Trop Med Hyg (in press).
2 Llanos-Cuentas EA, Marsden PD, Lago EL, Barreto AC, Cuba CC, Johnson WD. Human mucocutaneous leishmaniasis in Três Braços, Bahia-Brazil. An area of Leishmania braziliensis braziliensis transmission. II. Cutaneous disease: presentation and evolution. Rev Soc Bras Med Trop (in press).

3 Zeledon R. Efecto de la temperatura de la piel en la leishmaniasis cutanea experimental. Rev Soc Bras Med Trop 1971;5:131-4

作

Montenegro J. The inoculability of Leishmania. American fournal of Tropical Medicine 1924;4:331-40.

(Accepted 20 November 1984)

Tropical Medicine Unit of the University of Brasilia, Brazil

P D MARSDEN, MD, professor

E A ALMEIDA, MD, professor

E A LLANOS-CUENTAS, MD, professor

J L M COSTA, MD, professor

A V MEGALHÃES, MD, professor

N E PETERSON, PHD, professor

C C CUBA, PHD, professor

A C BARRETO, PHD, professor

Correspondence to: Professor P Marsden, Nucleo de Medicina Tropical e Nutricao, Universidade de Brasilia, CP 153121, 70.910, Brasilia DF, Brazil.

\section{Partial mastectomy alone in early breast cancer}

The clinical management of early breast cancer has evoked considerable controversy over the past 20 years, but the survival of patients with the disease has remained unchanged. Surgical procedures vary widely e'ren within a single centre. Most British surgeons prefer simple mastectomy or wedge excision and radiotherapy, ${ }^{1}$ though some still practise modified radical mastectomy. ${ }^{2}$ Worldwide practice varies from radiotherapy as primary treatment to extended radical mastectomy with excision of all nodal drainage areas. ${ }^{3}$ The optimum treatment for individual patients can best be evaluated by investigating all permutations and combinations of treatment through prospective clinical trials. The results of such studies show how little impact initial treatment has on survival, ${ }^{4}$ suggesting that the least aggressive approach possible should be used after diagnosis.

In 1971 one of us (RT) began a trial to study the results of partial mastectomy without supplementary radiotherapy. ${ }^{5}$ The study was ended because the incidence of local recurrence at three years was unacceptably high (37\%). We present a subsequent follow up.

\section{Patients, methods, and results}

We studied 37 patients with histologically proved invasive carcinoma (stages I and II). The series was consecutive, but patients were excluded if they had more than one primary growth; widespread peau d'orange; primary growths of affected axillary nodes fixed to the deep fascia; or less than $2 \mathrm{~cm}$ between the nipple and the growth's palpable edge. The growth was excised with $2 \mathrm{~cm}$ of normal tissue all around. Follow up was three monthly for the first three years, six monthly for two more years, and then yearly (nine to 13 years altogether). We also collected information from the Cambridge Cancer Registry on 330 patients with early breast cancer who presented in 1974. These patients had been managed conventionally with either a modified radical mastectomy or simple mastectomy; some had also received radiotherapy.

Primary tumours were $0.5-5.0 \mathrm{~cm}$ (average $2.0 \mathrm{~cm}$ ) in diameter. Five tumours were in medial, 26 in lateral, and six in intermediate positions in the breast. The axillary nodes were dissected out in 12 patients, but only nine showed histologically confirmed malignant disease.

Tumours recurred in 20 patients $(54 \%$ ), who were disease free for eight to 50 (average $24 \cdot 5$ ) months postoperatively. Local recurrences were defined as recurrences in the chest wall, axilla, or supraclavicular nodes. Tumours recurred locally in 15 patients $(40 \%)$, who survived three years or more, with a mean of 23 months before relapse. Nine patients with lateral, three with medial, and three with intermediary tumours developed recurrences in the same $\underset{T}{\square}$ breast. The mean diameter of these recurrences was $2.3 \mathrm{~cm}$. In all but one $z$ patient the recurrence lay immediately below the operation scar, suggesting that remaining malignant cells had colonised the wound. Seven patients with $\varrho$ histologically proved recurrences underwent total mastectomy, five axillary dissection, and three both. Five were disease free four years after treatment; $\Omega$ although in two of these the disease later recurred.

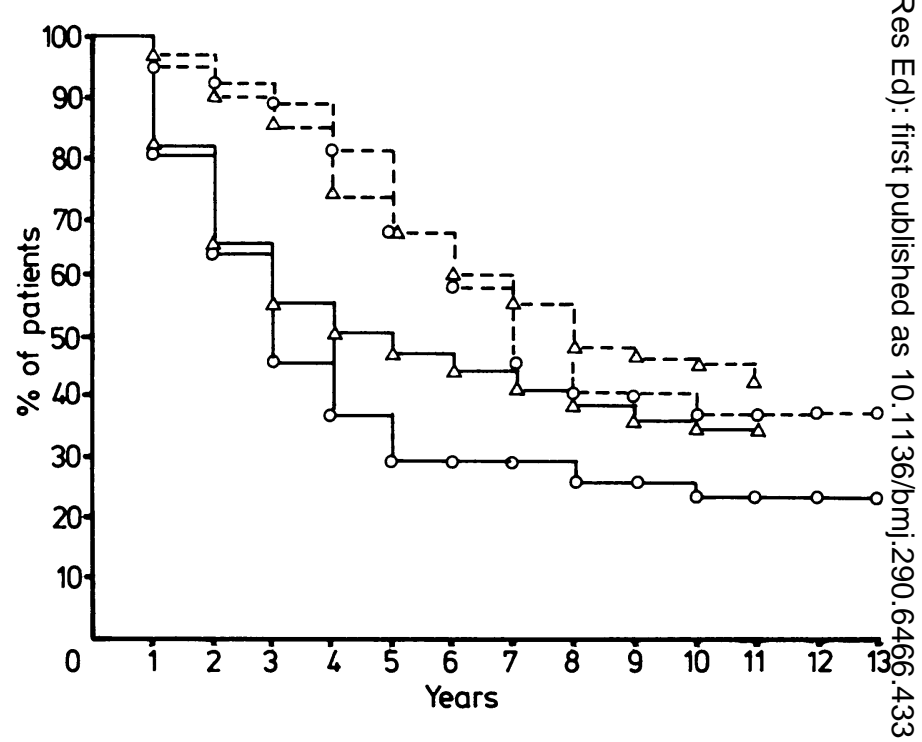

Disease free survival patterns in patients who had undergone partial mastec- 음 tomy $(O-\circlearrowleft)$ and controls $(\triangle-\triangle)$; and survival patterns corrected for age in patients $(0-\cdots)$ and controls $(\Delta-\cdots \Delta)$.

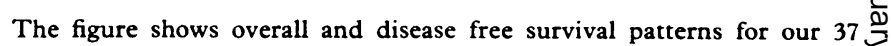
patients and the 330 patients in whom radical or simple mastectomy with or without radiotherapy was the primary treatment. Primary surgical treatment $\vec{c}$ clearly did not affect survival even when limited to partial mastectomy of alone.

\section{Comment}

This study shows that the results of minimal surgical intervention are similar to those of more aggressive approaches in terms of survival, despite the high incidence of local recurrence. This suggests that the $\overrightarrow{\vec{B}}$ type of the disease at presentation is more important than the surgical $\frac{0}{3}$ procedure used.

We believe that the controversy surrounding the management of $\frac{P}{0}$ early breast cancer is now over. Excision with radiotherapy is the most cosmetically acceptable treatment with the lowest overall morbidity. New advances require the successful management of systemic disease.

1 Baum $M$. The role of local treatment for primary carcinoma of the breast. Ann $R$ Coll Surg Engl 1978;60:479-82.

2 Patey DH, Dyson WH. The prognosis of carcinoma of the breast in relation to the type of operation performed. Br $\mathcal{f}$ Cancer $1948 ; 2 ;$.

Bluming AZ. Treatment of primary breast cancer without morbidity. Am f Med $1982 ; 72: 820-8$.

4 Veronesi U, Saccozzi R, Vecchio DM. Comparing radical mastectomy with 윽 quadrantectomy, axillary dissection, and radiotherapy in patients with small N 5 Tagart REB. Partial mastectomy for breast cancer. Br Med f 1978 ;ii: 1268.

(Accepted 23 November 1984)

Newmarket General Hospital, Newmarket, and West Suffolk Hospital, Bury St Edmunds IP33 2QZ

ROBIN TAGART, MCH, FRCS, consultant surgeon

Department of Radiotherapy, Addenbrooke's Hospital, Cambridge CB2 2QH

DAVID BRATHERTON, MB, FRCR, consultant radiotherapist

Ludwig Institute for Cancer Research, Addenbrooke's Hospital, Cambridge CB2 2QH

LOUISE HARTLEY, medical student

KAROL SIKORA, MRCP, FRCR, director and consultant radiotherapist

Correspondence to: Dr Karol Sikora. 